\title{
Simultaneous Encephalitis and Neuroretinitis After COVID-19 in a Young Adult: A Case Report
}

\author{
Maryam Poursadeghfard ${ }^{a}$, Maryam Sharifian-Dorche ${ }^{a}$, b, Alijan Nematic ${ }^{c}$ Ashkan Mowla ${ }^{\mathrm{d}}$ e
}

\begin{abstract}
Coronavirus disease 2019 (COVID-19) pandemic greatly impacted many aspects of life in the world. Both neurological and ophthalmologic presentations after COVID-19 have been reported. Herein, we present a case of both neuroretinitis and encephalitis after COVID-19 in a young adult. Both presentations are among the rare presentations of COVID-19. Similar manifestations were not reported previously. The 18-year-old previously healthy girl initially presented with low-grade fever, nausea, vomiting, body pain, and headache. The patient tested positive for severe acute respiratory syndrome coronavirus 2 (SARSCoV-2) by reverse transcriptase-polymerase chain reaction (PCR) by using a nasal swab. Two days after the onset of COVID-19 symptoms, she reported blurred vision in both eyes, progressing to only light perception in 3 days. Based on the ophthalmological evaluation, she was diagnosed with neuroretinitis. A few days later, she gradually became drowsy, so she was referred for neurological evaluation. Brain magnetic resonance imaging (MRI) showed bilateral medial temporal T2 and fluid-attenuated inversion recovery (FLAIR) hyper-signal lesions suggestive of encephalitis. A low-dose steroid was started to treat the neuroretinitis. After about 2 weeks, significant improvement in visual acuity and resolution of retinitis patches were observed. Our case is rare in respect of both neurological and ophthalmic involvement.
\end{abstract}

Keywords: Neuroretinitis; Encephalitis; COVID-19; SARS-CoV-2

\section{Introduction}

Coronavirus disease 2019 (COVID-19) pandemic continues to

Manuscript submitted July 25, 2021, accepted October 14, 2021

Published online October 26, 2021

${ }^{a}$ Clinical Neurology Research Center, Shiraz University of Medical Sciences, Shiraz, Iran

${ }^{b}$ Department of Neurology and Neurosurgery, Montreal Neurological Institute, McGill University, Montreal, QC, Canada

${ }^{\mathrm{c}}$ Khodadoust Eye Hospital, Shiraz, Iran

dDepartment of Neurological Surgery, Keck School of Medicine, University of Southern California (USC), Los Angeles, CA, USA

${ }^{\mathrm{e}}$ Corresponding Author: Ashkan Mowla, Division of Endovascular Neurosurgery, Department of Neurological Surgery, Keck School of Medicine, University of Southern California (USC), 1200 North State St., Suite 3300, Los Angeles, CA 90033, USA. Email: mowla@usc.edu

doi: https://doi.org/10.14740/jnr698 grow all over the world. There is increasing evidence of neurological manifestations in patients with COVID-19. Besides direct invasion of the virus to the central nervous system (CNS), coronavirus neurotropism was suggested to cause these manifestations [1-5].

In the other aspect, eye involvement in COVID-19 has been reported in several studies. Ocular symptoms are commonly present in patients with severe COVID-19 pneumonia; and it was shown that isolation of the severe acute respiratory syndrome coronavirus 2 (SARS-CoV-2) from the conjunctival sac was feasible in these patients. One of the most common presentations was conjunctivitis [6]. Other ophthalmologic presentations such as retinitis and choroiditis are rare [7,8].

Herein, we present a case of neuroretinitis and encephalitis post-COVID-19 diagnosis in a young adult. Both presentations are among the rare presentations of COVID-19. The ethical board of Shiraz University of medical sciences approved this study (Approval No: IR.sums.med.rec.1400.144).

\section{Case Report}

An 18-year-old previously healthy girl initially presented with low-grade fever, nausea, vomiting, body pain, and headache. The patient tested positive for SARS-CoV-2 by reverse transcriptase-polymerase chain reaction (PCR) using a nasal swab.

Two days after the onset of the COVID-19 symptoms, the patient reported blurred vision, which was progressed to light perception in 3 days in both eyes. The patient was referred to an ophthalmologist. Ophthalmology examination revealed poorly reacting pupils and a positive Marcus gunn (2+) in the left side. Funduscopic examination showed multiple bilateral white-yellowish placoid lesions located at the posterior pole and the mid-peripheral retina. The other findings were papillitis, peripapillary retinal hemorrhage, and edema, especially in the inner retinal layer, and macular edema. All findings were prominent in the left eye. There was no evidence of vitritis, uveitis, peripheral retinal change, or retinal vascular abnormality. In optical coherence tomography (OCT), we observed choroidal folds with an irregular overlying retinal pigment epithelium (RPE) and hyper-reflective spots in the choroid layer. Accordingly, she was diagnosed with neuroretinitis.

For evaluation of neuroretinitis, laboratory examinations including the complete blood cell (CBC) count and examinations for liver, thyroid, renal function, and serum vitamin B12 levels were performed, which showed normal findings. All serology tests for different infections like cat-scratch disease, 

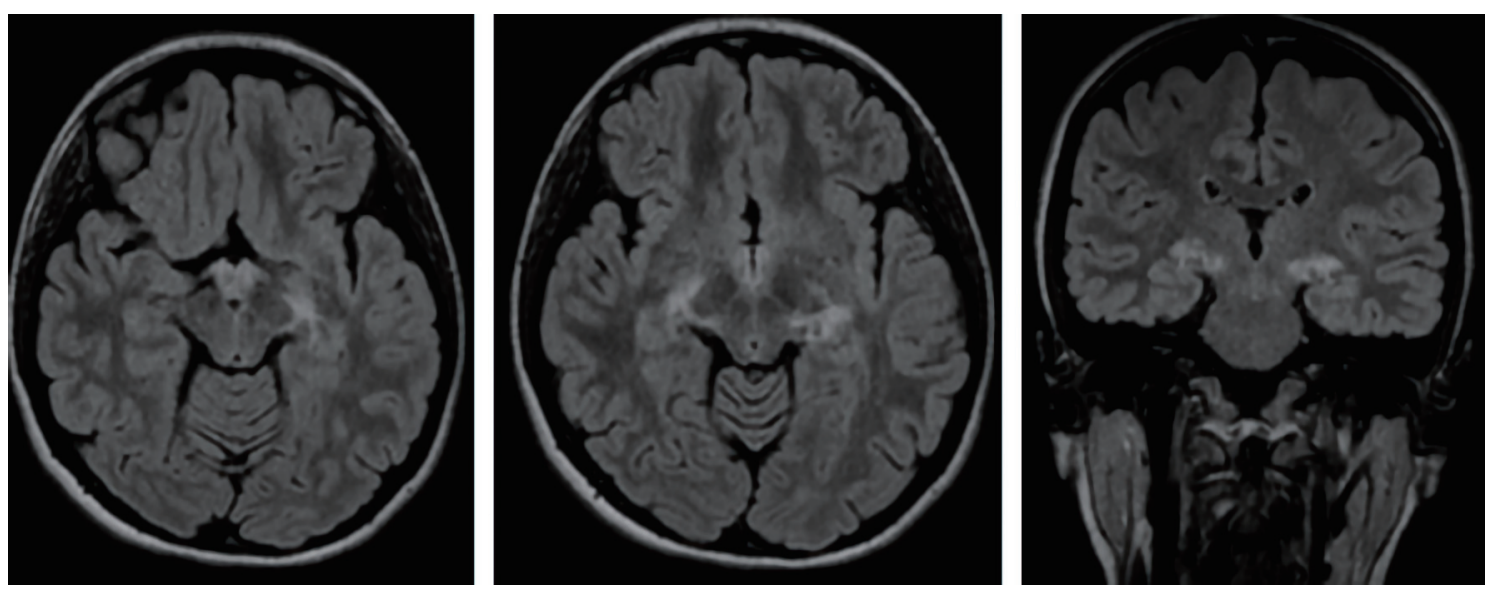

Figure 1. Axial and coronal views of brain MRI show FLAIR increased signal intensity in the cortical and subcortical regions of both mesial temporal lobe and both side hippocampal tails with a relatively symmetrical appearance. MRI: magnetic resonance imaging; FLAIR: fluid-attenuated inversion recovery.

toxoplasmosis, syphilis, Lyme disease, brucellosis, human immunodeficiency virus (HIV), varicella zoster virus (VZV), herpes simplex virus (HSV), cytomegalovirus (CMV), Epstein-Barr virus (EBV), and hepatitis $\mathrm{B}$ and $\mathrm{C}$ were negative. Angiotensin-converting enzyme (ACE) levels for sarcoidosis and purified protein derivative (PPD) tests were negative. She was also checked for a probable undetected autoimmune disease which was not conclusive (erythrocyte sedimentation rate (ESR), antinuclear antibodies (ANA), double-stranded DNA, $\mathrm{C} 3$, and $\mathrm{C} 4$ ). $\mathrm{CBC}$ and other biochemistry tests were normal. Therefore, we ruled out systemic autoimmune and infectious processes that could present similar clinical features in this case.

A few days later, she gradually became drowsy; however, clinical seizures, decreased level of consciousness, or behavioral changes were not reported. Due to progressive drowsiness, she was referred to a neurologist for a better neurological evaluation. In neurological examination, she did not have a neurological deficit except for mild drowsiness and minimal delay in mental processing. Brain magnetic resonance imaging (MRI) was performed, which showed evidence of T2 and fluid-attenuated inversion recovery (FLAIR) increased signal intensity in the cortical and subcortical regions of both mesial temporal lobe as well as both side hippocampal tails, with relative symmetrical appearance without evidence of significant enhancement or restricted diffusion in diffusion-weighted imaging (DWI) compatible with viral or autoimmune encephalitis (Fig. 1). Therefore, SARS-CoV-2-associated encephalitis was suggested. The patient and her family disagreed with further investigations and lumbar puncture.

To evaluate COVID-19 involvement of the lung, a highresolution CT (HRCT) of the chest was performed, which was normal.

Her past medical, drug consumption, and personal histories did not show any significant point.

Drowsiness was recovered in 10 days without treatment, and a low-dose steroid was started for 2 weeks to treat the neuroretinitis. After treatment, significant improvement in visual acuity and resolution of retinitis patches were observed.

\section{Discussion}

The present study reported a patient who developed neuroretinitis and encephalitis a few days after being diagnosed with SARS-CoV-2 infection. COVID-19 has a range of clinical presentations from asymptomatic infection to severe respiratory failure and death [5]. Neuro-ophthalmic manifestations are among the less common features. In addition, neurotropism of the virus has been shown. Recently, the viral infection of CNS by SARS-CoV-2 was confirmed by detecting the virus in brain tissues and capillary endothelial cells at autopsy [1].

The virus can penetrate CNS via trigeminal (signal changes seen in the brainstem and thalamus) and olfactory (increased FLAIR signal in the medial temporal lobe) nerve endings $[9,10]$. The other possible route of entry may increase the permeability of the blood-brain barrier (BBB) due to high pro-inflammatory cytokines in the cerebrospinal fluid (CSF) during infection [11]. Thus, encephalitis and meningoencephalitis following COVID-19 may be caused by the entrance of the virus via these routes of invasion, which has been reported in several case reports $[5,12]$.

In COVID-19, involvement of both the brain and ophthalmic tissues is rare. One possible explanation may be the role of the ACE2 receptor, a functional receptor for SARS-CoV-2. ACE2 receptor has a high expression in the conjunctiva and endothelium of the brain vessels like lung mucosa and gastrointestinal duct [13]. Thus, the virus can enter the cells via these receptors.

On the other hand, ophthalmologic presentations after COVID-19 are less frequent than neurological presentations. Among ophthalmologic manifestations, conjunctivitis is the most common presentation [6].

From the beginning of the pandemic, direct or indirect contamination of the conjunctival epithelium with infectious droplets was suggested as a possible route of transmission of COVID-19 [14]. The ocular surface can serve as a reservoir for SARS-CoV-2. The eye can be contaminated with SARSCoV-2 by hand-eye contact and aerosols, and then the virus 
Table 1. Clinical Presentations of Retinal Involvement After COVID-19

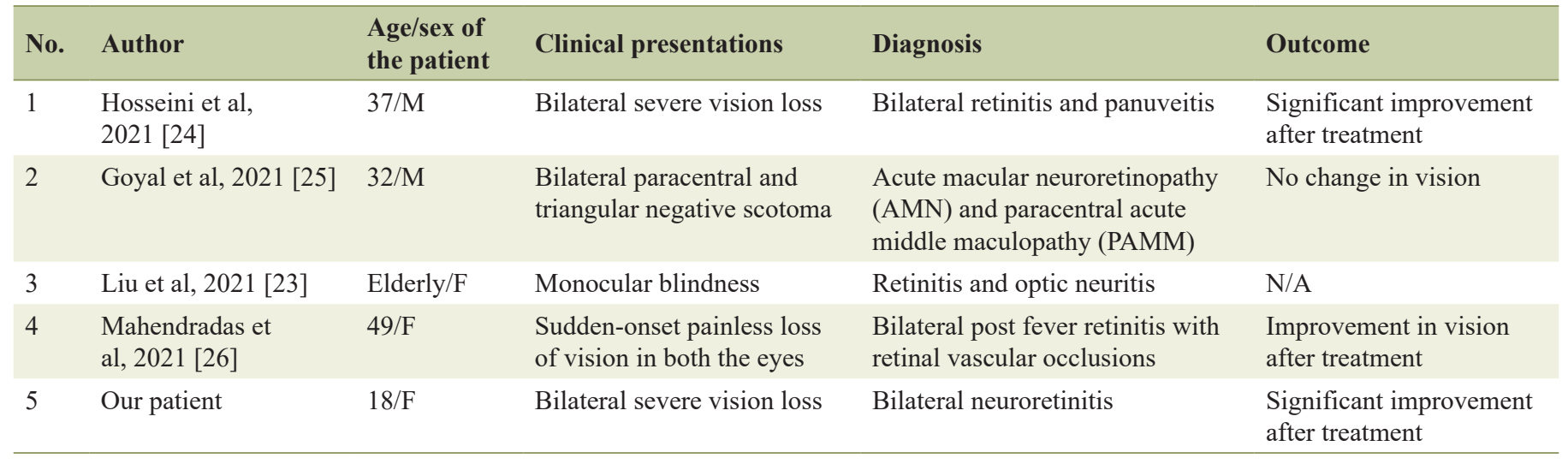

Similar presentation (bilateral involvement) was seen in three cases; in most of these patients significant improvement was seen after treatment (similar as our patient). COVID-19: coronavirus disease 2019; M: male; F: female; N/A: not applicable.

can transfer to other systems through the nasolacrimal route and hematogenous metastasis [15]. Eye involvement after other types of coronavirus infection has been evaluated several times. For example, in animal models, anterior uveitis, choroiditis, vasculitis, and retinitis were reported in other types of coronavirus infection [16]. However, in SARS-CoV-2, these types of involvements are not frequent [6].

Ophthalmic tissue involvement and visual impairment in SARS-CoV-2-infected patients might be associated with several underlying pathophysiologies, including infection of lacrimal glands (dacryoadenitis), conjunctivitis choroiditis, tonic pupils, vitritis, central retinal artery/vein occlusion (CRAO/ CRVO), retinitis, retinal bleeding (in some reports bilateral retinal hemorrhages), panuveitis, anterior ischemic optic neuropathy $(\mathrm{AION})$, optic neuritis, optic perineuritis, optic nerve stroke, or occipital ischemic stroke. Interestingly, it was shown that visual impairment could be the initial manifestation of COVID-19 [17-21].

Sim et al [22] reported retinal microvascular changes on ocular imaging of the patients with COVID-19, even in asymptomatic patients. They suggested that these retinal microvascular signs could be related to underlying cardiovascular and thrombotic alternations related to COVID-19.

Overall, retinal involvement after COVID-19 was reported only in few case reports (Table 1) [23-26]. Liu et al reported acute viral retinitis in patients with COVID-19 and severe acute monocular blindness [23].

Hosseini et al reported bilateral neuroretinitis and panuveitis in a 37-year-old male patient with a history of recovered COVID-19. This patient had similarities with our patient regarding bilateral involvement; however, encephalitis was not reported in this case [24].

Moreover, optic neuritis has been reported in COVID-19 patients and may occur with or without affection of other cranial nerves $[27,28]$.

Burgos-Blasco et al [29] reported that SARS-CoV-2 might affect the optic nerve and cause changes in the retinal layers even at the stage in which the infection has resolved. As such, in patients with COVID-19 and decreased vision, before diagnosing SARS-CoV-2-associated optic nerve involvement, oth- er differentials need to be excluded [28]. It has been reported that SARS-CoV-2 may cause endothelial damage, thrombus formation, and thromboembolism; accordingly, ophthalmologic vascular complications such as AION, CRAO and CRVO [30-36]. Therefore, they should be considered in the differential diagnoses list in the cases of vision loss after SARS-CoV-2 infection [28].

Despite these ophthalmic and neurological presentation reports, the coincidence of neurological presentations and ophthalmic presentations after COVID-19 is rare [37].

Other neurological manifestations such as headache and ocular and periocular pain have been described in cases with ophthalmic presentations [38]. However, it should be considered that headache is a prevalent clinical presentation in COVID-19 and may be seen in several patients [9]. In some case reports, third nerve palsy and sixth nerve palsy with peripheral neuropathy suggestive of Miller Fisher syndrome were reported with COVID-19 [39]. However, the coincidence of encephalitis and neuroretinitis after COVID-19 is very rare.

This rare coincidence (encephalitis and neuroretinitis) was reported in the other viral infections too. There are reports of similar presentation in the patients infected with HSV [40], VZV [41], Japanese encephalitis (JE) virus [42], pseudorabies virus [43], and Rift Valley fever virus (RVFV) [44].

Interestingly, during the COVID-19 pandemic, besides reports of neuroretinitis after SARS-CoV-2, there were also reports of reactivation of acute retinal necrosis due to HSV after COVID-19 in few cases $[45,46]$.

In our patient, the eye might have been contaminated with SARS-CoV-2 through hand-eye contact and aerosols and then transferred to the CNS through the nasolacrimal route [15]. Involvement of both medial temporal lobes may show this transmission via the olfactory nerve. Ocular involvement may occur in the mid-phase of COVID-19 illness. Viral SARS-CoV-2 ribonucleic acid (RNA) was detected in conjunctival swabs of the patients even without ocular manifestations, after resolution of conjunctivitis, and even after nasopharyngeal swabs turned negative, and in the retina of deceased COVID-19 patients [38].

Lacks of CSF evaluation and PCR from the vitreous sam- 
ple were the most important limitations in this study, excluding other possible etiology in this patient.

In the aspect of MRI findings related to encephalitis after COVID-19, several patterns of MRI were reported. Temporal lobe encephalitis (which was seen in our patient) was among the most common MRI presentations in these patients. As mentioned before, this finding may relate to the route of entry of the virus in these patients [47].

In conclusion, the ocular surface remains a potential transmission route for the virus to other people and other organs, such as the brain of the patients themselves [39]. Therefore, we recommend that all health care providers get familiarized with SARS- CoV-2 infection complications, particularly neurological involvement in the presence of acute ophthalmologic presentations with or without systemic symptoms [38].

\section{Acknowledgments}

The authors would like to thank Shiraz University of Medical Sciences, Shiraz, Iran, and also the Center for Development of Clinical Research of Nemazee Hospital and Dr. Nasrin Shokrpour for editorial assistance.

\section{Financial Disclosure}

None to declare.

\section{Conflict of Interest}

The authors declare that they have no relevant conflict of interest to report.

\section{Informed Consent}

Informed consent was obtained from the patient.

\section{Author Contributions}

All authors have contributed to data collection, data analysis and writing of the manuscript.

\section{Data Availability}

The authors declare that data supporting the findings of this study are available within the article.

\section{Abbreviations}

PCR: polymerase chain reaction; MRI: magnetic resonance imaging; COVID-19: coronavirus disease 2019; CNS: central nervous system; OCT: optical coherence tomography;
RPE: retinal pigment epithelium; $\mathrm{CBC}$ : complete blood cell; ACE: angiotensin-converting enzyme; ESR: erythrocyte sedimentation rate; ANA: antinuclear antibodies; DWI: diffusionweighted imaging; CRAO: central retinal artery occlusion; CRVO: central retinal veins occlusion; AION: anterior ischemic optic neuropathy; HIV: human immunodeficiency virus; CMV: cytomegalovirus; EBV: Epstein-Barr virus; PPD: purified protein derivative; JE: Japanese encephalitis; RVFV: Rift Valley fever virus

\section{References}

1. Shahjouei S, Naderi S, Li J, Khan A, Chaudhary D, Farahmand G, Male S, et al. Risk of stroke in hospitalized SARS-CoV-2 infected patients: A multinational study. EBioMedicine. 2020;59:102939.

2. Mowla A. Stroke care during the COVID-19 pandemic; A global challenge. Iran J Med Sci. 2020;45(5):323-324.

3. Vahabizad F, Sharifian Dorche M, Mohammadi P, Khatibi $\mathrm{K}$, Mowla A. COVID-19-related acute ischemic stroke in young adults: what is the optimal antithrombotic regimen for secondary prevention? J Neurol Res. 2020;10(5):203206.

4. Sharifian-Dorche M, Sahraian MA, Fadda G, Osherov M, Sharifian-Dorche A, Karaminia M, Saveriano AW, et al. COVID-19 and disease-modifying therapies in patients with demyelinating diseases of the central nervous system: A systematic review. Mult Scler Relat Disord. 2021;50:102800.

5. Sharifian-Dorche M, Huot P, Osherov M, Wen D, Saveriano A, Giacomini PS, Antel JP, et al. Neurological complications of coronavirus infection; a comparative review and lessons learned during the COVID-19 pandemic. J Neurol Sci. 2020;417:117085.

6. Amesty MA, Alio Del Barrio JL, Alio JL. COVID-19 disease and ophthalmology: an update. Ophthalmol Ther. 2020;9(3):1-12.

7. Pirraglia MP, Ceccarelli G, Cerini A, Visioli G, d'Ettorre G, Mastroianni CM, Pugliese F, et al. Retinal involvement and ocular findings in COVID-19 pneumonia patients. Sci Rep. 2020;10(1):17419.

8. Ortiz-Seller A, Martinez Costa L, Hernandez-Pons A, Valls Pascual E, Solves Alemany A, Albert-Fort M. Ophthalmic and neuro-ophthalmic manifestations of coronavirus disease 2019 (COVID-19). Ocul Immunol Inflamm. 2020;28(8):1285-1289.

9. Bolay H, Gul A, Baykan B. COVID-19 is a real headache! Headache. 2020;60(7):1415-1421.

10. Virhammar J, Kumlien E, Fallmar D, Frithiof R, Jackmann S, Skold MK, Kadir M, et al. Acute necrotizing encephalopathy with SARS-CoV-2 RNA confirmed in cerebrospinal fluid. Neurology. 2020;95(10):445-449.

11. Poyiadji N, Shahin G, Noujaim D, Stone M, Patel S, Griffith B. COVID-19-associated acute hemorrhagic necrotizing encephalopathy: imaging features. Radiology. 2020;296(2):E119-E120.

12. Romero-Sanchez CM, Diaz-Maroto I, Fernandez-Diaz E, Sanchez-Larsen A, Layos-Romero A, Garcia-Garcia J, 
Gonzalez E, et al. Neurologic manifestations in hospitalized patients with COVID-19: The ALBACOVID registry. Neurology. 2020;95(8):e1060-e1070.

13. Reinhold A, Tzankov A, Matter M, Mihic-Probst D, Scholl HPN, Meyer P. Ocular pathology and occasionally detectable intraocular SARS-CoV-2 RNA in five fatal COVID-19 cases. Ophthalmic Res. 2021.

14. Mirza E, Mirza GD, Belviranli S, Oltulu R, Okka M. Ocular-symptoms-related Google Search Trends during the COVID-19 Pandemic in Europe. Int Ophthalmol. 2021;41(6):2213-2223.

15. Qu JY, Xie HT, Zhang MC. Evidence of SARS-CoV-2 transmission through the ocular route. Clin Ophthalmol. 2021;15:687-696.

16. Seah I, Agrawal R. Can the coronavirus disease 2019 (COVID-19) affect the eyes? A review of coronaviruses and ocular implications in humans and animals. Ocul Immunol Inflamm. 2020;28(3):391-395.

17. Abrishami M, Emamverdian Z, Shoeibi N, Omidtabrizi A, Daneshvar R, Saeidi Rezvani T, Saeedian N, et al. Optical coherence tomography angiography analysis of the retina in patients recovered from COVID-19: a casecontrol study. Can J Ophthalmol. 2021;56(1):24-30.

18. Monferrer-Adsuara C, Castro-Navarro V, Gonzalez-Giron N, Remoli-Sargues L, Ortiz-Salvador M, Montero-Hernandez J, Cervera-Taulet E. A case of bilateral unusual retinal hemorrhages in a COVID-19 patient. Eur J Ophthalmol. 2020:1120672120984381.

19. de Souza EC, de Campos VE, Duker JS. Atypical unilateral multifocal choroiditis in a COVID-19 positive patient. Am J Ophthalmol Case Rep. 2021;22:101034.

20. Providencia J, Fonseca C, Henriques F, Proenca R. Serpiginous choroiditis presenting after SARS-CoV-2 infection: A new immunological trigger? Eur J Ophthalmol. 2020:1120672120977817.

21. Finsterer J, Scorza FA, Scorza CA, Fiorini AC. SARSCoV-2 impairs vision. J Neuroophthalmol. 2021;41(2): 166-169.

22. Sim R, Cheung G, Ting D, Wong E, Wong TY, Yeo I, Wong CW. Retinal microvascular signs in COVID-19. Br J Ophthalmol. 2021.

23. Liu L, Zhen HM, Shen Y. COVID-2019 associated with acquired monocular blindness: could be central artery occlusion or viral uveitis ? Curr Eye Res. 2021:1-2.

24. Hosseini SM, Abrishami M, Zamani G, Hemmati A, Momtahen S, Hassani M, Omidtabrizi A. Acute bilateral neuroretinitis and panuveitis in a patient with coronavirus disease 2019: a case report. Ocul Immunol Inflamm. 2021;29(4):677-680.

25. Goyal M, Murthy SI, Annum S. Retinal manifestations in patients following COVID-19 infection: A consecutive case series. Indian J Ophthalmol. 2021;69(5):1275-1282.

26. Mahendradas P, Hande P, Patil A, Kawali A, Sanjay S, Ahmed SA, Thomas S, et al. Bilateral post fever retinitis with retinal vascular occlusions following severe acute respiratory syndrome corona virus (SARS-CoV2) infection. Ocul Immunol Inflamm. 2021:1-6.

27. Sharma A, Kudchadkar US, Shirodkar R, Usgaonkar UPS, Naik A. Unilateral inferior altitudinal visual field defect related to COVID-19. Indian J Ophthalmol. 2021;69(4):989-991.

28. Finsterer J, Scorza FA, Scorza CA, Fiorini AC. Vascular damage may mimic retinitis and optic neuritis in COVID-19. Curr Eye Res. 2021:1-2.

29. Burgos-Blasco B, Guemes-Villahoz N, Vidal-Villegas B, Martinez-de-la-Casa JM, Donate-Lopez J, Martin-Sanchez FJ, Gonzalez-Armengol JJ, et al. Optic nerve and macular optical coherence tomography in recovered COVID-19 patients. Eur J Ophthalmol. 2021:11206721211001019.

30. Mowla A, Shakibajahromi B, Shahjouei S, BorhaniHaghighi A, Rahimian N, Baharvahdat H, Naderi S, et al. Cerebral venous sinus thrombosis associated with SARS-CoV-2; a multinational case series. J Neurol Sci. 2020;419:117183.

31. Shakibajahromi B, Borhani-Haghighi A, Haseli S, Mowla A. Cerebral venous sinus thrombosis might be underdiagnosed in the COVID-19 era. eNeurologicalSci. 2020;20:100256.

32. Ostovan VR, Foroughi R, Rostami M, Almasi-Dooghaee M, Esmaili M, Bidaki AA, Behzadi Z, et al. Cerebral venous sinus thrombosis associated with COVID-19: a case series and literature review. J Neurol. 2021;268(10):35493560 .

33. Mowla A, Sizdahkhani S, Sharifian-Dorche M, Selvan P, Emanuel BA, Tenser MS, Amar AP, et al. Unusual pattern of arterial macrothrombosis causing stroke in a young adult recovered from COVID-19. J Stroke Cerebrovasc Dis. 2020;29(12):105353.

34. Shahjouei S, Anyaehie M, Koza E, Tsivgoulis G, Naderi S, Mowla A, Avula V, et al. SARS-CoV-2 is a culprit for some, but not all acute ischemic strokes: a report from the multinational COVID-19 stroke study group. J Clin Med. 2021;10(5):931.

35. Jafari Khaljiri H, Jamalkhah M, Amini Harandi A, Pakdaman H, Moradi M, Mowla A. Comprehensive review on neuro-COVID-19 pathophysiology and clinical consequences. Neurotox Res. 2021;39(5):1613-1629.

36. Dmytriw AA, Phan K, Schirmer C, Settecase F, Heran MKS, Efendizade A, Kuhn AL, et al. Ischaemic stroke associated with COVID-19 and racial outcome disparity in North America. J Neurol Neurosurg Psychiatry. 2020;91(12):1362-1364.

37. Luis ME, Hipolito-Fernandes D, Mota C, Maleita D, Xavier C, Maio T, Cunha JP, et al. A review of neuroophthalmological manifestations of human coronavirus infection. Eye Brain. 2020;12:129-137.

38. Jin YP, Trope GE, El-Defrawy S, Liu EY, Buys YM. Ophthalmology-focused publications and findings on COVID-19: A systematic review. Eur J Ophthalmol. 2021;31(4):1677-1687.

39. Chen Z, Yuan G, Duan F, Wu K. Ocular Involvement in Coronavirus Disease 2019: Up-to-date information on its manifestation, testing, transmission, and prevention. Front Med (Lausanne). 2020;7:569126.

40. Patil S, Beck P, Nelson TB, Bran A, Roland W. Herpes simplex virus-2 meningoencephalitis with abducens nerve palsy with literature review. Cureus. 2021;13(6):e15523.

41. Tizazu EF, Chang G, Berger JR. Varicella zoster virus 
(VZV) oculomeningoencephalomyeloradiculitis: a previously undescribed constellation. J Neurovirol. 2020;26(3): 433-436.

42. Van K, Korman TM, Nicholson S, Troutbeck R, Lister DM, Woolley I. Case report: japanese encephalitis associated with chorioretinitis after short-term travel to Bali, Indonesia. Am J Trop Med Hyg. 2020;103(4):1691-1693.

43. Hu F, Wang J, Peng XY. Bilateral necrotizing retinitis following encephalitis caused by the pseudorabies virus confirmed by next-generation sequencing. Ocul Immunol Inflamm. 2020:1-4.

44. Bamia A, Marcato V, Boissiere M, Mansuroglu Z, Tamietti C, Romani M, Simon D, et al. The NSs protein encoded by the virulent strain of rift valley fever virus targets the expression of $\mathrm{Abl} 2$ and the actin cytoskeleton of the host, affecting cell mobility, cell shape, and cell-cell adhesion. J Virol. 2020;95(1).

45. Soni A, Narayanan R, Tyagi M, Belenje A, Basu S. Acute Retinal Necrosis as a presenting ophthalmic manifestation in COVID 19 recovered patients. Ocul Immunol Inflamm. 2021;29(4):722-725.

46. Gonzalez MP, Rios R, Pappaterra M, Hernandez M, Toledo A, Santos C, Emanuelli A, et al. Reactivation of acute retinal necrosis following SARS-CoV-2 infection. Case Rep Ophthalmol Med. 2021;2021:7336488.

47. Bahranifard B, Mehdizadeh S, Hamidi A, Khosravi A, Emami R, Mirzaei K, Nemati R, et al. A review of neuroradiological abnormalities in patients with coronavirus disease 2019 (COVID-19). Neuroradiol J. 2021:19714009211029177. 